\title{
First report of tobacco mosaic virus infecting Hosta longipes in Korea
}

\author{
Nam-Yeon Kim ${ }^{1} \cdot$ Hyo-Jeong Lee ${ }^{1} \cdot$ Na-Kyeong Kim ${ }^{1} \cdot$ Hongsup Kim ${ }^{2} \cdot$ Rae-Dong Jeong ${ }^{1}$ (C)
}

Received: 27 May 2020 / Accepted: 10 September 2020 / Published online: 16 September 2020

(C) Società Italiana di Patologia Vegetale (S.I.Pa.V.) 2020

Keywords Hosta longipes $\cdot$ Korea $\cdot$ Tobacco mosaic virus

Hosta longipes (Family Asparagaceae) is a perennial herb that grows mostly in the dry, mountainous regions of Korea, eastern Russia, China, and Japan. In July 2019, virus-like symptoms, such as obvious mosaic, mottling, and foliage discoloration, were observed on $H$. longipes plants in a botanical garden in Naju city, Korea. To identify the causal virus, leaf samples from five symptomatic plants of $H$. longipes were randomly collected, and the leaf dip preparation was analyzed by transmission electron microscopy. Tobamovirus-like particles of rigid rod shapes (about $300 \times 18 \mathrm{~nm}$ length/width) were observed in all the $H$. longipes samples. A further ten symptomatic leaf samples of $H$. longipes were analyzed using double-antibody sandwich-ELISA kits (Agdia, Elkhart, IN, USA) to verify if the virus was one of the major tobamoviruses reported in Korea, such as pepper mild mottle virus, tobacco mild green mosaic virus, and tobacco mosaic virus (TMV). All of the symptomatic H. longipes samples tested positive for TMV only. Total RNA was extracted from the 10 ELISA-positive samples using the Clear-S Total RNA extraction kit (InVirusTech Co., Korea). RT-PCR was performed using TMV-specific primers designed from a highly conserved region of the coat protein $(\mathrm{CP})$ gene $\left(5^{\prime}\right.$-ATGT C T T A C A G T A T C A C T C C - 3', and 5' - TCAA GTTGCAGGACCAGAGGT-3') (Choi et al., 2009). The expected RT-PCR products of approximately $436 \mathrm{bp}$ were amplified in the symptomatic samples. The amplicons were purified, cloned into the pGEM-T Easy Vector (Promega,
Madison, WI), and sequenced in both directions. The sequences were all identical; one representative sequence was deposited in GenBank (LC417446). The TMV isolate had 99\% nucleotide identity with the CP gene of TMV isolates from Nicotiana tabacum (HE818443) and Solanum lycopersicum (JX993906). To fulfil Koch's postulates, virusfree $H$. longipes (10 plants) were mechanically inoculated with sap from TMV-HI-infected $H$. longipes, and all plants showed mosaic symptoms at 20 dpi on systemic leaves. These samples also tested positive for TMV by RT-PCR, and the RT-PCR product was identical to that of TMV-HI. To our knowledge, this is the first report of the occurrence of TMV in H. longipes in Korea.

Funding This research was financially supported by the National Research Foundation of Korea (NRF) grant funded by the Korea government (MSIP) (No. 2017R1C1001873).

\section{Reference}

Choi S-K, Yoon J-Y, Chung B-N (2009) Genome analysis and characterization of a tobacco mosaic virus isolate infecting balsam (Impatiens balsamina). Arch Virol 154:881-885

Publisher's note Springer Nature remains neutral with regard to jurisdictional claims in published maps and institutional affiliations.
Rae-Dong Jeong

jraed2@jnu.ac.kr

1 Department of Applied Biology, Institute of Environmentally Friendly Agriculture, Chonnam National University, Gwangju 61185, South Korea

2 Seed testing \& research center, Korea seed \& variety service, Gimcheon 39660, South Korea 